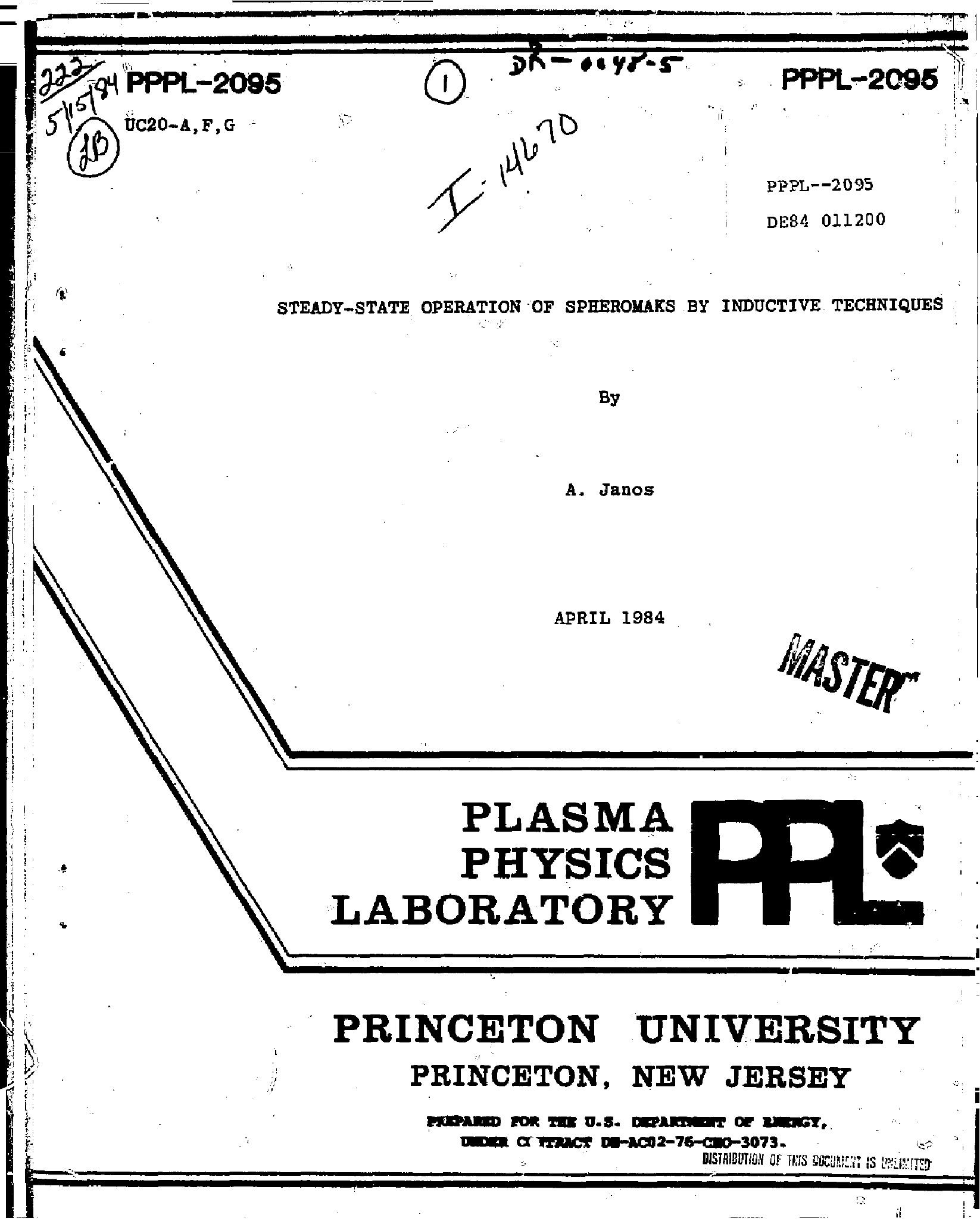

5151 .

$(\beta)^{\mathrm{UC} 20-A, F, G}$

STEADY-STATE OPERATION OF SPHEROMARS BY INDUCTIVE TECHNIQUES
APRIL 1984

\title{
PRINCETON UNIVERSITY
}

PRINCETON, NEW JERSEY

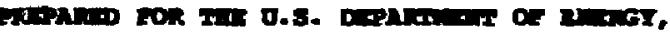

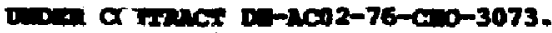

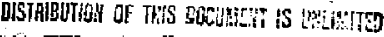




\author{
A. Janos \\ Plasma Physics Laboratory, Princeton University \\ Princeton, New Jersey 08544
}

\begin{abstract}
A method to maintain a steady-gtate spheronak configuration inductively using the 5-1 Spheromak device is described. The s-1 Spheromak formation apparatus can be utilized to inject magnetic heliclty continuously (C.W., not pulsed or D.C.) into the spheromak configuration after equilibrium is achieved In the "linked" mode of operation. Dscillation of both poloidal- and toroldal-field currents in the flux core ( $\psi-\phi$ Pusping), with proper phasing, injects a net time-averaged helicity into the plasma. steady-gtate maintenance relies on flux conversion, which has boen earlier identified. Relevant experimental data from the operation of $5-1$ are described. Helicity flow has been meagured and the proposed injection scheme simulated. In a reasonable tiue practlcal voltages and fxequencies can inject an amount of hellcity comparable to that in the initial plasma. Plasro currents can be maintained or increased. This pumping technique $1 \mathrm{~s}$ similar to $E-\theta$ pumping of a Reversed-Field-Pinch but $1 \mathrm{~s}$ applied to this "inverse-pinch" formation.
\end{abstract}

\title{
DISCLAIMER
}

\footnotetext{
This report was prepared as an account of work sponsored by an agency of the United States employees, makes any wame United States Government nor any agency thercof, nor any of their bility for the accuracy, cempleteness, or usefulness, or assumes any legal liability or responsiprocess disclosed, or represents that its use weuld of any information, cpparatus, nroduct, or erce herein to any specific commercial product, process, or serivately owned rights. Refermanufacturer, or otherwise does not necessarily process, or service by trade name, trademark, mendation, or favoring by the United States Government or imply its endorsement, recomand opinions of authors expressed herein do novernment or any agency thereof. The views United States Government or any agency thereof.
}

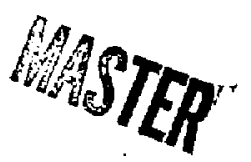




\section{INTRODUCFION}

Steady-state or long-pulse operation of a fusion reactor has many advantages over pulsed operation. The possibility for gteady-gtate operation of spheromaks has relied so far on one of a number of unproven schemes: radio-frequency curcent drive, beam injection, or merqing ${ }^{\dagger}$ of newly created spheromaks with previously established, but decaying, ones. steady-gtate spheromak drive has been proposed 2,3 by use of electrodes, as well.

The S-1 Spheromak induction technique 4 lends itself not only to the formation of spheromaks, but also to the induetive sugtainment of a steadystate spheromak. The $s-1$ formation apparatus can be utilized to inject magnetlc helicity $x=f \underline{A}$ - $\underline{B} d V$ into the spheromak configuration after equilibrium is achieved in order to maintain or increase plasma currents. This steady-state inductive operation has been made possible by three recent developments. The firgt is the positive identiflation 5 of flux conversion processes and relaxation phenomena in the s-1 spheromak plasma. These phenomena are consistent wth the spontaneous approach to a Taylor state. 6 Relaxation is an essential requirement for steady-state drive. The plasma is relied on to assimilate properly the fluxes input to it to maintain adequate profileg. A second development is the favorable stahility afforded by operation in the "linked" mode;" the spheromak is not completely detached from the core, so some poloidal magnetic flux links both the plasth ant vhe core. This minimal linkage provides the coupling to external eircuits needed for continuously driving the plasma currents. The third development is the proposal of F-O Pumping ${ }^{8-11}$ in RFg devices. There is a significant similarity between operation of Reversed-Fleld-Pinch poloidal- and toroidal-field clrcuits and operation of the s-1 3pheromak "inverse-pinch" circuits. 
The combination of these developients allowa sustalnatent of spheromaks yia access to only the outermost flux surfacen, The spheromak configuration can be maintained in a highly stable and controlled fashion. The method described below eliminates the restriction to pulsed spheromak plasmas or the use of electrodes for steady-state operation, and, therefore, is a reactorrelevant formation and sugtainment method. The inductive formation and equjibrium of these spheronaks have already been experinentally tested and proven ${ }^{4}$ so that only tie steady-gtate drive technique needg tegting.

The purposes of this report are to dascribe this new method of maintaining a steady-atate spheromak plasma configuration by inductive techniques, to present the pertinent experimental data from the S-1 Spheromak device, and to describe a gimple ginulation of the steady-state drive.

\section{STEADY-STATE TECHNIQUES}

This continuous (C.W.) uethod injects magnetic helicity fr Jm the flux core into the already formed spheromak conflguration by appropriately ascillating the currents in the poloidal- and toroldal-field circuits (Eig. 3a.). This method requireg the spheromak to be operated in the linked mode; that is, the spheromak would be formed in the same manner as usual, but would not be completely detached from the core (Fig. 1). Hereatter, an oscillation of both poloidal- and toroidal-field currents in the core commences. A net helicity is injected from the core into the plasma on an average over a period of oscillation. The phasing is chosen to maximize the average helicity input rate. This $\psi-\phi$ pumpling works because of the nonlinear behavior of the magnecics. It is analogoug to what RFP researchers call F- $\Theta$ Pumping. This pumping technique has two immediate advantages over some of the other pulsed techniques: the injection is continuous and controllable; and it 
operates in the stable linked mode. Without a stabilizing system or method, plaspas either tilt $c$ s ohift aftor completely detaching, depending on the equilibrium fleld shape. Increased stabllity againat tilting and shifting has been demongtrated ${ }^{7}$ by not fully detaching the ephoromak from the core. The linked mode provides both a vary stable plasma and the necessary coupling between the plasna and core.

III. HELICITY INJECTION

A. Basic equations for s-1 Spheromak topology

It can be ghown that the proper definition of the magnetic helicity for the linked spheromak topology is

$$
K \equiv \int \underline{A} \cdot \underline{B} d \mathbf{V}-\psi \phi .
$$

This ensures that the helleity is gauge invariant. A is the vector potential; $\underline{B}=\nabla \times \underline{A}$ is the magnetic fleld vector. The integral is over the plasma volume. The magnetic fluxes $\psi$ and $\phi$ are defined by

$$
\psi=\int \underline{\mathbf{A}} \cdot \stackrel{\mathrm{aR}}{\phi}
$$

and

$$
\phi=\int \underline{A} \cdot \underline{d^{2}} \theta
$$

where the Ilne integrals of the vector potentlal axe taken the long and the short way around the flux core, respectively. 
The plasma has the two surfaces $s_{1}$ and $s_{2}$ to coneider in the linked mode, as is shown in Fig. 1. The surface $s_{1}$ between the plasga and the core can be considered a constant flux surface. This is oxperimentally true for several reasons. First, the flux core poloidal fleld system and the equilibrium field system are designed so that, at the moment the plasma is initiated, the vactum pololdal flux intercepting the core surface is uinimized. Second, there ts an aluminum shell, with poloidal and toroidal cuts, embedded in the core between the surface and the coils; this smooths Field ripple and maintains a more nearly constant flux surface at the coce surface throughout the digcharge. Hence, $\underline{B} \cdot \underline{d S}=0$ on $s_{1}$. The surface $s_{2}$ is definec by the outermost poloidal field line enclosing the plasma so that $\underline{B}$ $\underline{\mathrm{d} S}=0$ identically.

The time dependence of $\mathrm{K}$ is obtained by taking the time derivative of Eq. (1):

$$
\frac{\partial K}{\partial t}=\int\left[\frac{\partial A}{\partial t} \cdot \underline{B}+\underline{A} \cdot \frac{\partial_{B}}{\partial t}\right] d V+\int(\underline{A} \cdot \underline{B}) \underline{v} \cdot \underline{d S}-\frac{\partial}{\partial t}(\psi \phi) \cdot
$$

The remainder of this section is devoted to reformulating this expression for $\partial_{K} / \partial_{t}$ using ohmic logs terms and the fluxes and voltages associated with the core.

Using Faraday's Law, Eq. (3) becomes

$$
\frac{\partial K}{\partial t}=-\int[\underline{B} \cdot(\underline{E}+\nabla \theta)+\underline{A} \cdot \nabla \times \underline{E}] d V+\int(\underline{A} \cdot \underline{\underline{B}}] \underline{\mathbf{y}} \cdot \underline{d S}-\frac{\partial}{\partial t}(\psi \phi),
$$


where $\theta$ is a calar potential. The tera in $\underline{B} \cdot \nabla \theta$ is zero because $B$ - dS $=0$ on both plasma surfaces:

$\int_{\underline{B}} \cdot \nabla \theta d v=\int \nabla \cdot\left(\theta_{B}\right) d V=\int \theta \underline{B} \cdot d \underline{S} \cdot$

The tirgt integral in Eq. (4) can be rewritten using a vector identity and Gauss' Theorem, so that

$$
\frac{\partial K}{\partial t}=-2 \int \underline{E} \cdot \underline{B} d v+\int(\underline{A} \times \underline{E}) \cdot \underline{d s}+\int(\underline{A} \cdot \underline{B}) \underline{y} \cdot \underline{d S}-\frac{\partial}{\partial t}(\psi \phi) \cdot
$$

The third integral on the right-hand side of Eq. (6) can be rewritten by uge of a rector identity as $\int \underline{\underline{A}} \times(\underline{\mathbf{y}} \times \underline{B})+(\underline{A} \cdot \underline{\underline{y}} \underline{\underline{B}}) \cdot \underline{\mathrm{aS}}$, so that

$$
\frac{\partial K}{\partial t}=-2 \int \underline{E} \cdot \underline{B} a v+\int \underline{A} \times(\underline{E}+\underline{v} \times \underline{B}) \cdot \underline{a S}+\int(\underline{A} \cdot \underline{v}) \underline{B} \cdot \underline{d S}-\frac{\partial}{\partial t}(\psi \phi) .
$$

The third integral in Eq. $(7)$ is zero as B AS $* 0$. The surface integral of $\underline{A} \times(\underline{Y} \times$ B) is zero at the core surface as $\underline{y}$ is parallel to the surface.

The second integral over surface $s_{2}$ can be shown to be negligible. using Ohm's law, this integral is just

$$
\int_{S_{2}} \underline{A} \times(\underline{E}+\underline{v} \times \underline{B}) \cdot \underline{d S}=\int_{s_{2}} \underline{A} \times \eta \underline{j} \cdot \underline{d S} .
$$

However, $I$ and $I$ are nearly, if not exactly, paraljel on $s_{2}$ since the plasma is expected to be maintaining a force-free state. The vector potential $A$ is only poloial on $s_{2}$, and the only current, if any, expected on the outer 
surface for reasonable discharges would be poloidal. The same integral over surface $s_{1}$ is nonzero since there exist both poloidal and toroldal components of both $j$ and $\underline{A}$ on $s_{1}$. The plasma is being driven through the $s_{1}$ surface. Hence, we get

$$
\begin{aligned}
\frac{\partial K}{\partial t} & =-2 \int \underline{E} \cdot \underline{B} d v+\int_{s_{1}} \underline{A} \times \underline{E} \cdot \underline{d s}-\frac{\partial}{\partial t}(\psi \phi) \\
& =-2 \int \underline{E} \cdot \underline{B} d v+\dot{\phi}-\psi \dot{\phi}-\frac{\partial}{\partial t}(\psi \phi) . \\
& =-2 \int \underline{E} \cdot \underline{B} d v-2 \psi \dot{\phi} .
\end{aligned}
$$

B. Helicity loss term The first term in Eq. (11) can be rewritten using Ohm's law, $\underline{E}+\underline{v} \times \underline{B}=$ 证, as

$$
-2 \int \underline{E} * \underline{B} d v=-2 \int \eta \underline{j} \cdot \underline{B} d v .
$$

Assuming force-free fields so that $\nabla \times \underline{B}=\underline{{ }_{B}}$, then $\underline{I}=\underline{\mu}$, The first tern in Eq. (11) becomes $-(2 / \mu) \int \pi j^{2}$ dv. This term is simply the decrease in hellaty due to ohnic losges. 
During early times when the plasma is forming around the core, the . magnitude of this loss term $-2 \int \underline{E} \cdot \underline{B} \mathrm{dv}$ nugt be smaller than that of the helicity inpus term $-2 \psi \phi$ in order for helicity to be built up in the plagma. This loss tem can be estimated ${ }^{12}$ as follows. Since $E \cdot \underline{B}=\underline{\mathrm{j}}$. $\underline{B}$ ard the resistivity is low except near the plasma edge, the volume over which this integral is significant becones a shell acound the core, so that

$$
-2 \int \underline{E} \cdot \underline{B} d v *-2 \delta \int \underline{E} \cdot \underline{\underline{\theta}} d S=-2 \delta \int\left(E_{\phi} B_{\phi}+E_{\theta} B_{\theta}\right) d s \text {, }
$$

where

$$
\begin{aligned}
& E_{\phi}=-\frac{\dot{\psi}}{2 \pi R_{c}}, \\
& E_{\theta}=-\frac{\dot{\phi}}{2 \pi a_{c}}, \\
& B_{\phi}=-\frac{\phi}{\pi a_{c}^{2}}, \\
& B_{\theta}=\frac{\psi}{\pi R_{c}^{2}}
\end{aligned}
$$

and where $R_{c}$ and $a_{c}$ are the major and minor radii of the flux core, respectively, and $\delta$ is some effective skin depth. Substituting Eq. (14) into (13):

$$
-2 \int \underline{E} \cdot \underline{B} d v * c \delta\left(\frac{-\dot{\psi} \phi}{\mathrm{a}_{c}}+\frac{\dot{\phi} \psi}{\mathrm{R}_{c}}\right) \text {. }
$$


This is small compared to the input term if $2 \delta / a_{c} \ll 1$. Since the plasma width around the core is experimentally already smaller than the core radius, $\delta$ also has to be sraller than $a_{c}$, and the inequality can easily be satisfied.

C. Helicity input term

The second term in Eq. (11) can be written as

$$
\left(\frac{\partial K}{\partial t}\right)_{1 n}=24 \%
$$

where $\$$ is the experimentally measured toroldal flux inside the core and $\Psi$ is the experimentaliy measured poloida? flux between the device axis and the core surface. This sign convention is chosen to conform to that used to display the experimental data below and also to make the plasma helicity a nonnegative quantity.

It turag out that it is the poloidal flux and toroidal flux change which contribute to the helicity in the $s-1$ Induction soheme, whereas it is the toroidal flux and polotdal flux ehange which contribute in the RFP techaique. This is due to the "inverse-pinch" topology of the s-1 technique.

Combining Eqs. (11), (12), and (16) regults in

$$
\frac{\partial K}{\partial t}=-2 \int \eta_{j} \cdot \underline{B} d V+2 \Psi \dot{\phi} .
$$

Steady state requires $\partial \mathrm{K} / \partial \mathrm{t}=0$, or

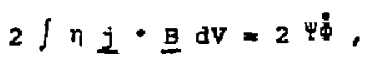


wheraln the helicity injection fust companates for the ohmic losses.

D. Linked requirement for basic equilibrium "target" plasua

In order to have a nonzero hellcity input, the right-hand side of Eq. (16) must be nonzero. This means, hiugt be nonzero, or-some pololial flux must link both the plasma and the core.

E. Prograrining of $\Psi$ and $\phi$

The right-hand side of Eq. (16) involuse both the poloidal- and toroidal-fieid clrcuits. This scheme to inject hellalty involves oscillation of both circults around some equilibrlum values, wth the proper phasing, so that the time average $\left.\langle 2 \Psi \dot{\phi}\rangle_{t}\right\rangle 0$.

Hellcity input requires

$$
2 \Psi>0
$$

Let the flux functions during the steadymstate drive phase be

$$
\begin{aligned}
& \Psi=\Psi_{0}+\Psi, \cos \omega t \\
& \Phi=\phi_{0}+\phi_{1} \cos (\omega t+\delta) .
\end{aligned}
$$

where $\delta$ is some phase shift. Substitution of Eq. (20) into Eq. (19) and averaging over time results in

$$
\left\langle 2 \Psi \phi_{t}=-\omega \Psi \phi_{1} \sin \delta\right.
$$


This average is a maximun when $\sin \delta=-1$, or when $\delta=-\pi / 2$, Then the maximum average helicity ingut rate is

$$
\left\langle\frac{\partial K}{\partial t}\right\rangle_{\text {in, } \max }=\omega \Psi_{1} \phi_{1} .
$$

The resulting flux functions during the steady-state drive phase are therefore

$$
\begin{aligned}
& \Psi=\Psi_{0}+\Psi_{1} \cos \omega t \\
& \phi=\Phi_{0}+\Phi_{1} \cos \left(\omega t-\frac{\pi}{2}\right),
\end{aligned}
$$

as shown in Fig. 3a. The maximum average helicity input rate relative to the peak-to-peak swing of the helicity input rate is

$$
\frac{\langle\partial \mathrm{K} / \partial \mathrm{t}\rangle_{\text {in, } \max }}{\partial \partial \mathrm{K} / \partial \mathrm{t})_{\mathrm{P}-\mathrm{P}}}=\frac{1}{2} \frac{\left(\Psi_{1} / \Psi_{0}\right)^{2}}{\left(\Psi_{1} / \Psi_{0}\right)^{2}+\left(\Psi_{1} / \Psi_{0}\right)+1 / 4}
$$

and is increased when $\Psi_{1} / \Psi_{0}$ is increased. The ratio $\Psi_{1} / \Psi_{0}$ cannot be greater thain one, otherwise the plasma is no longer coupled to the core during part of a cycle.

Higher pumping frequencies are better, but a limit is set by the skin time of the flux core liner. With higher frequencies, there is also a practical upper voltage limit for the power supplies and coil systems. Higher modulation in the toroidal $f l u x$ is also better. The normalized helleity input rate $\dot{k} / K$ should be larger than the inverse clasgical diffusion time but maller than the inverse relaxation time in order for the plasma to assinilate the input fluz into a relaxed state before the configuration decays. 
IV. EXPERIHENTAI, RESULTS AND SIHULATED STEADY-STATE DRTVE The experimental reaulte from a typictal linked alscharge in s-1 are shown in Fig. 2a-c. The fluxes and voltages are obtalned fron wire loops enbedded in the core just beneath the surface. The fact that the poloidal flux does not return to zero indicates that the gpheronak plagma is Btill coupled to the flux core as in Fig. 1. The resulting rate of helicity ingut $\checkmark$ from "the core"

$$
\left(\frac{\partial K}{\partial t}\right)_{\perp I}=2 \Psi \dot{\phi}
$$

and the leaulting helicity are shown in Eig. 2b. Injected helicity reaches a constant value approximately $0.3 \mathrm{msec}$ after the plasma is initiated. The resulting experimentally seasured toroidal plasma current and flux are shown in Fig. 2c.

The same discharge is used to represent, or model, the first 0.6 msec of a continuously driven spheromak (FIg. 3). Then the poloidal flux is modulated with ${ }^{\Psi_{1}} / \Psi_{0}=0.68$ and the toroldal flux with $\phi_{1} / \Phi_{0}=0.21$ (Fig. 3a). The resulting peak voltages are on the order of $1 \mathrm{kV}$ and $0.25 \mathrm{kV}$, respectively. This $\psi-\phi$ pumping may be understood as follows. Toroidal flux is inductively transferred to the plasma during that part of the cycle for which there is a relatively large coupling ( $\Psi$ large) between plasma and core, so a relatively large amount of helicity is added. Toroidal flux is inductively removed from the plasma during that part of the cycle for which there is a relatively sma11 coupling ( $\Psi$ small) between plasma and core, so a relatively small amount of helicity ig extracted. The lnput helicity increases neally linearly in time at a rate of approxtmately 6.67 volt $\mathrm{gec}^{2}$ per msec for this case. The 
helleity doubles from tts value before $\psi$ - $\phi$ punping in approximately 4.5 mgec. (No losses are considered in this computation,) There is evidence 5 of relaxation tines in $5-1$ on the order of 50 Hsec. The requirenent that the characteristic helicity input time be larger than the relaxation tise but comparable or shorter than the diffusion tine can easily be aatisfied with further optimization and/ce hotter plasmas.

v. CONCLUSIONS AND DISCUSSIL,V

By coupling the spheromak to a flux core, we have transformed a singly connected configuration into a doubly connected one, wherein the $[(\underline{A} \times \underline{E}) \cdot \underline{d S}]$ contribution to helicity injection can be made large and inductive current drive in spheronaks can become practical. This $\psi / \phi$ Pumping can be used to either maintain of increage the plasma helicity (plagma currents .

There is no guarantee that relaxationg will completely integrate the fluxes into proper profiles, espectally for very hot plasmas (T $\gg 100 \mathrm{eV}$ ). Flux conversion seems to work particularly well during formation as the flu: is being added to the outermost, cold surfaces of the plasm. The interior of the plasma may not relax as well. Further investigation of higher-temperature spheromaks is necessary.

\section{ACKHOWLEDGKENTS}

I would like to acknowledge valuable discugsions with Dr. A, Reipan. This work was supported by the U.S. Department of Energy Contract ko. DE-ACO2-76-CHO-3073. 


\begin{abstract}
REFERENCES
'T.' Sato, S. Otsuka, K. Araki, "Formation and Merging of Spherome.ks and Formation of FRC, " in Proceedings of the Fourth Symposium on the Physics and Technology of Compact Toroids, (LLL, Livermore, 1981), p. 112.

2.E. Jensen and M.S. Chu, "A class of Steady state Compact Tori," Proceedings of the Fifth Symposium on the Physics and Technology of compact Toroids, (MSNW, Seattle, 1982), D. 174 ,

3.R. Jarboe et al., "Slow Formation and sustainment of Spheromaks by a Coaxial Magnetized Plasma Source," Phys. Rev. Lett. 51 (1), 39 (1983); and T.R. Jarboe, "Steady State Spherorak," Proceedings of the Fifth Symposium on the Physics and Technology of Compact Toroids, (MSN,, Seattle, 1982), p. 169.
\end{abstract}

4. Yamada, H,F. Furth, พ. Hsu, A. Janos, S. Jardin, M. Okabayashi, J. Sinnis, T.H. Stix, K. Yamazaki, "Quasistatic Formation of the spheromak Plasma Configuration," Phys. Rev. Lett. 46, 188-191 (1987).

5A. Janos, "Relaxation Phenomena, Flux Conversion, and Global Magnetics of S-1 Spheromak Plasmas," Princeton Plasma Physics Laboratory Report No. PPPL-2066 (in process).

6.B. Taylor, "Relaxation of Toroidal Plasma and Generation of Reverse Hagnetic Fields," "Phys. Rev. Lett. $33,1139-1141$ (1974). 
7A. Janos, C. Munson, S. Paul, F. Wysocki, M. Yamada, "Equilibrium and Stability of Proto S-1 Spheromak," Fourth U.S.-Japan Horkshop on Compact Toroids, Osaka, Japan, October 1982, in Proceedings of the Fourth us-Japan Workshop on Compact Torolis, (Osaka University, Osaka, 1982), pp. 88-ioj.

8.K. Bevir and J.w. Gray, MRelaxation, Flux Consumption and quasi steady State Pinches," Proceedilıg of the Reversed-Field Pinch Theory Horkshop, (Los Alamos National Laboratory, Los Alamos, 1980), 1982, P. 239, LASL Report LA-B944-C.

${ }^{9}$ K.F. Schoenberg, R.F. Gribble, and D.A. Baker, "Oscillating Iield Current Drive for Reversed-Field Pinch Discharges," Los Alamos National Laboratory report LA-9161-MS (1981), submitted to I. Appl. Bhys.

10.F. Schoenberg, R.F. Gribble, and J.A. Philligs, "Zero Dimensional Simulations of Reversed-Field Pinch Experiments," Nucl. Fusion 22, 1433$1441,1982$.

${ }^{11}$ K.F. Schoenberg et al., "F-Theta Pumping and Field Modulation Experiments on a Reversed Field Pinch," to be published Phys. 'luids, March, 19a4.

12 . Reiman, private communication. 
FIGURE CAPTIONS

FIG. 1 Flux surfaces of an inductively formed spheromak without conplete detachment from flux core. The shaded portion indleates the plasma volume. Thi is called a lisked digcharge.

FIs. 2-a. Time histories of fluxes and voltages for a typical, inductively formed spheronak in the linked mode. From top-to-bottom: the poloidal flux $\Psi$ coupled by the flux core, the torotdal flux $\$$ inside the flux core, the agsociated time derivatives of these fluxes.

FIG. 2-b The rate of heliclty injection $(\partial \mathrm{K} / \partial \mathrm{t})_{1 \mathrm{n}}=2 \Psi \phi$ and the resulting net input helicity $\int_{0}^{t} 2 \%$ dt as a function of tiae.

FIG. 2-c Regulting experimentally measured plasma toroidal current and flux for this discharge.

FIG. 3-a Time histories of fluxes and voltages for the same inactively formed epheromak as above, but an oscillation of poloidal and toroidal fluxes is intiated at time 0.6 msec into the discharge in order to oupply helicity continuously.

FIG. 3-b The heliclty input rate and resulting net input hellcity for $\mathbb{W} \phi$ Pumping. Note that the helicity input doublea in about 4.5 msec with punping. 
\#84x0146

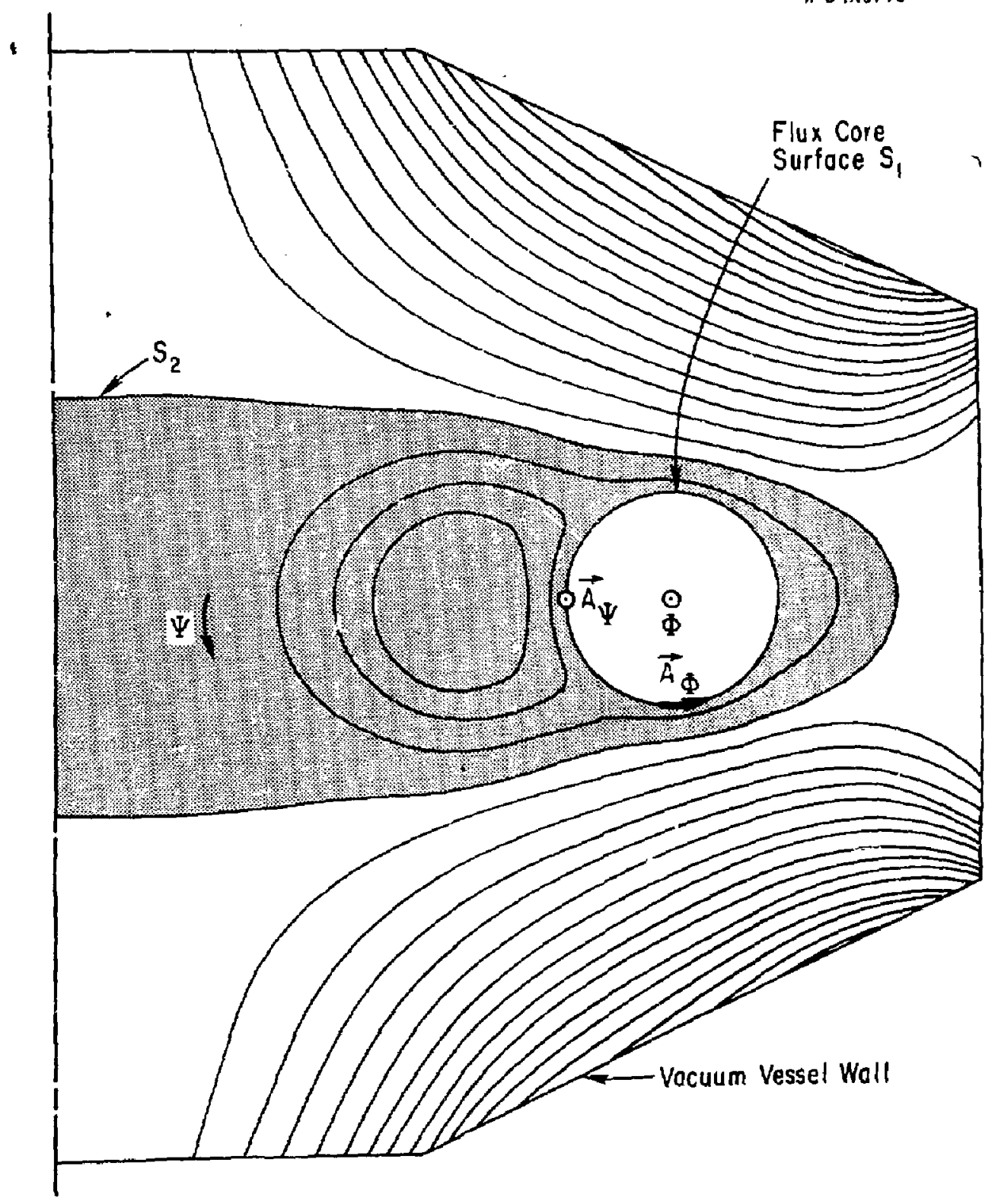

Eis. 1 
*84x0145
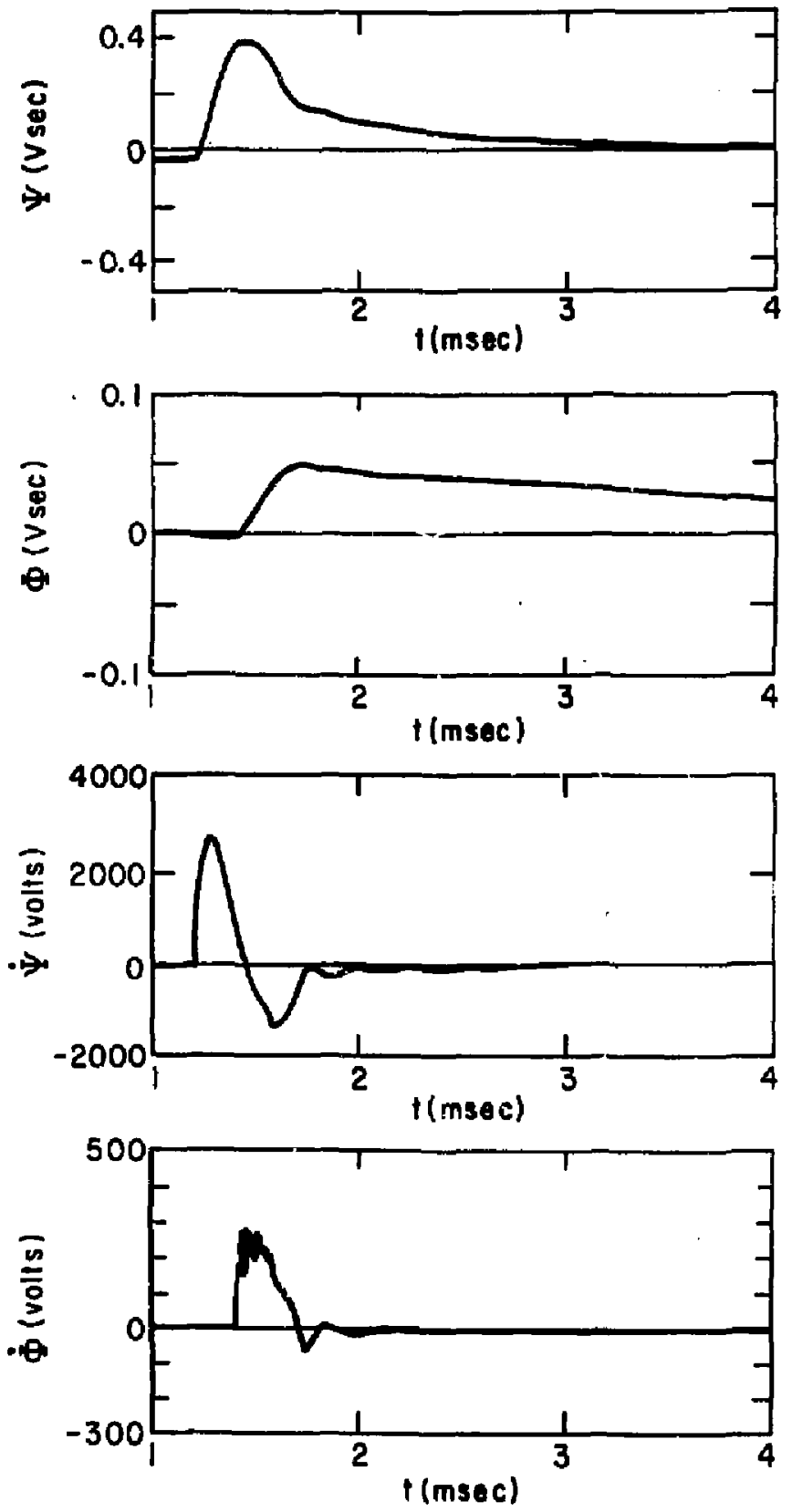

Fig. 2a 
\#84X0144
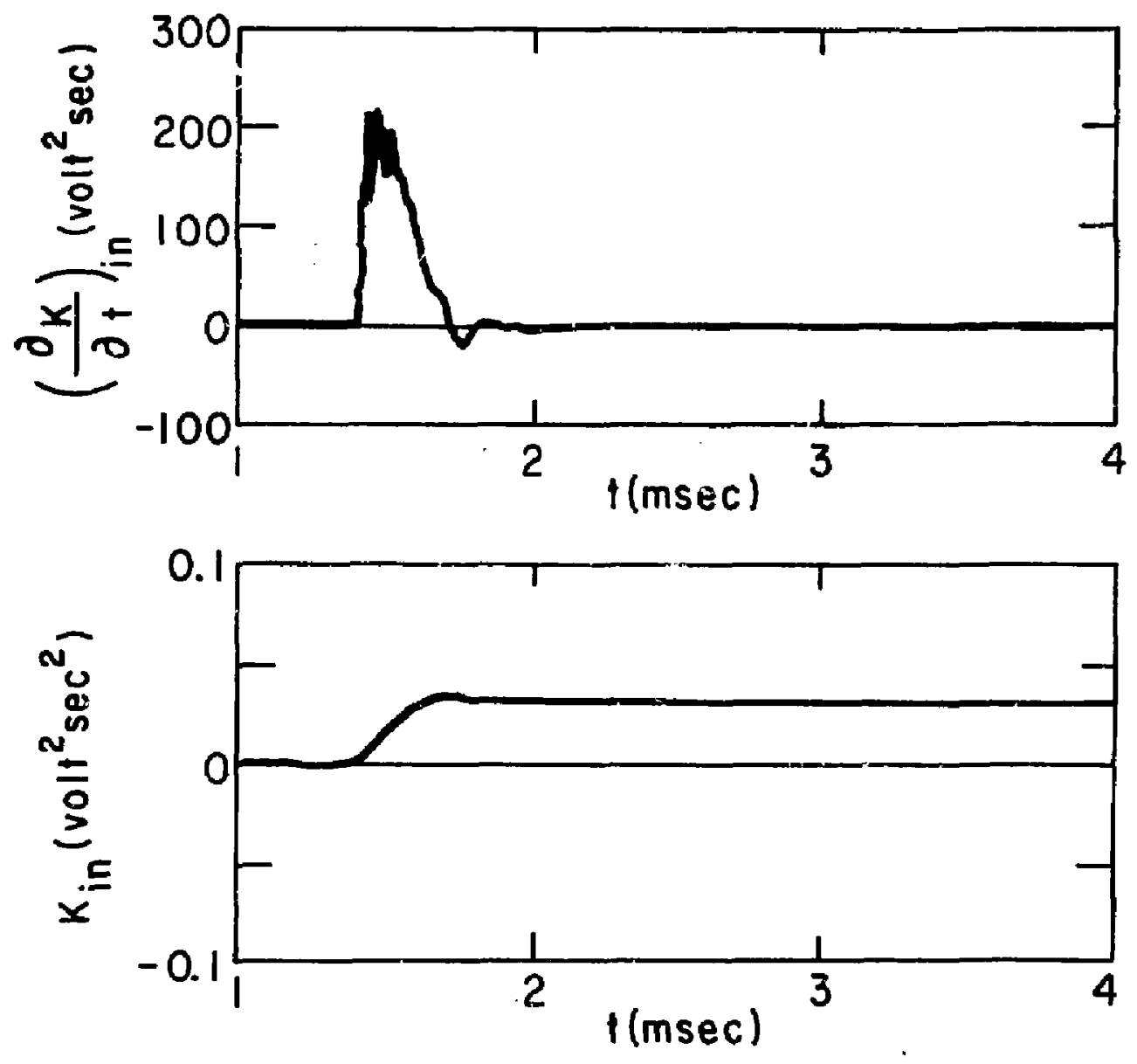

Fig. 2b 

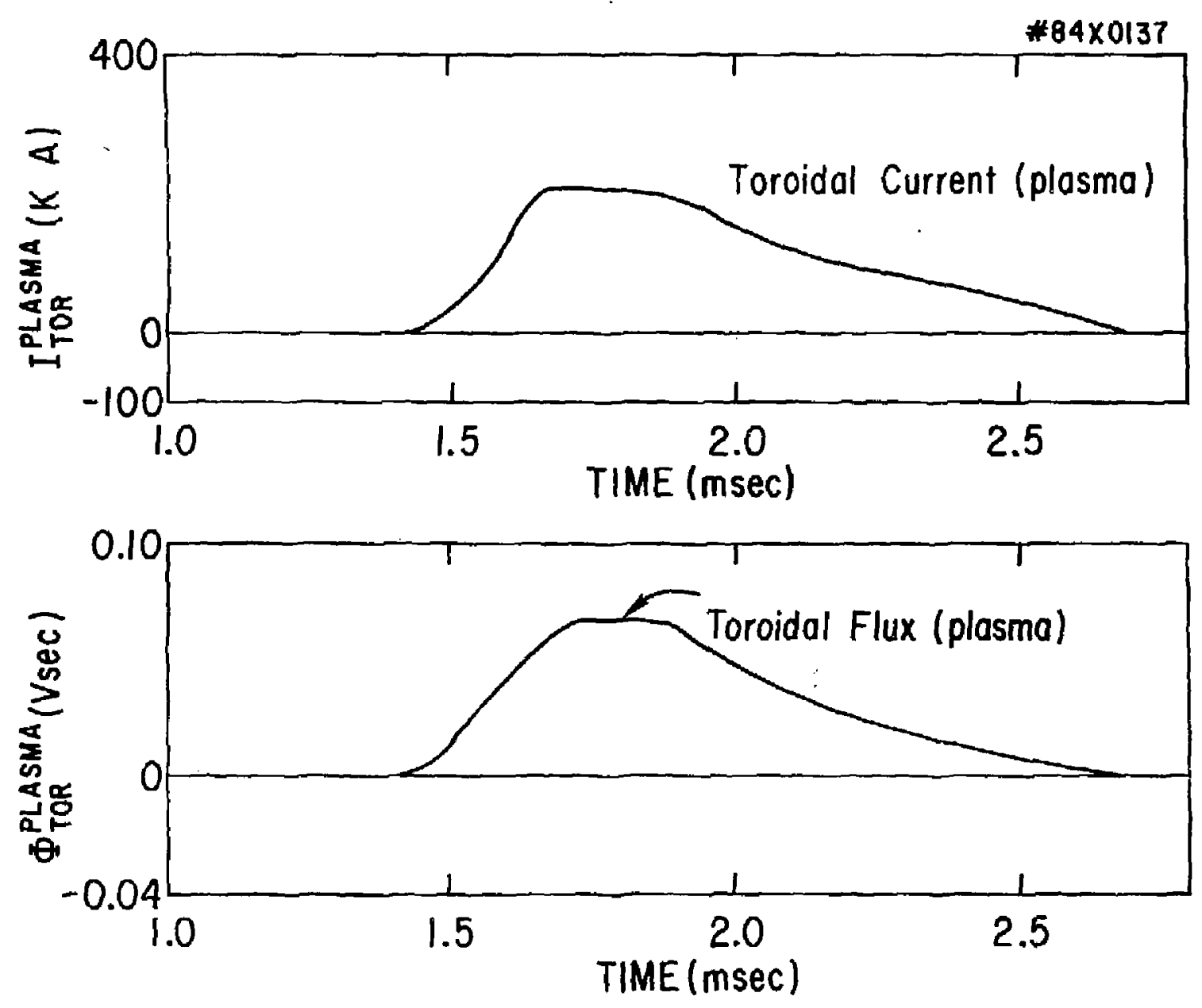

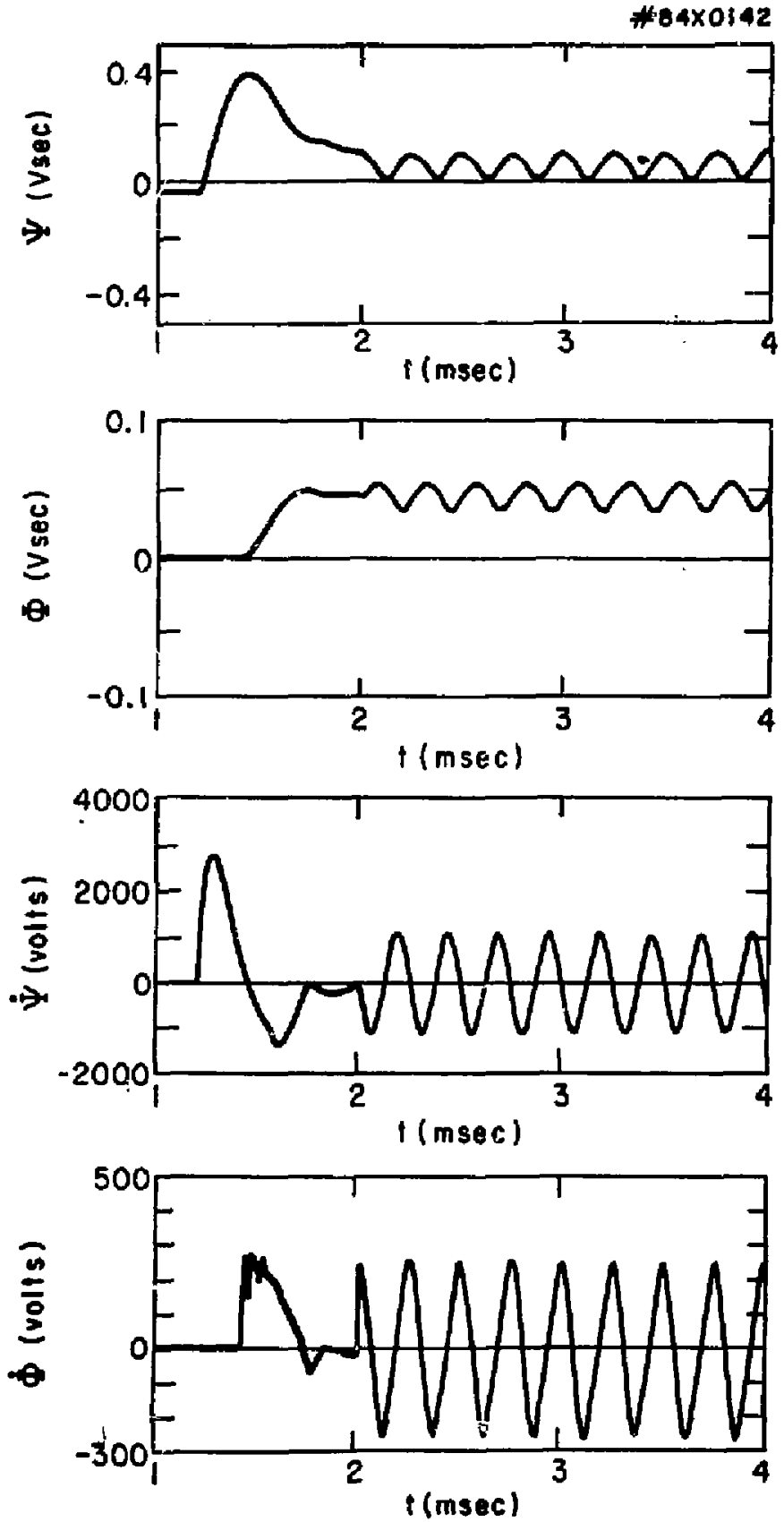

Fig. 3a 
\#84X0143
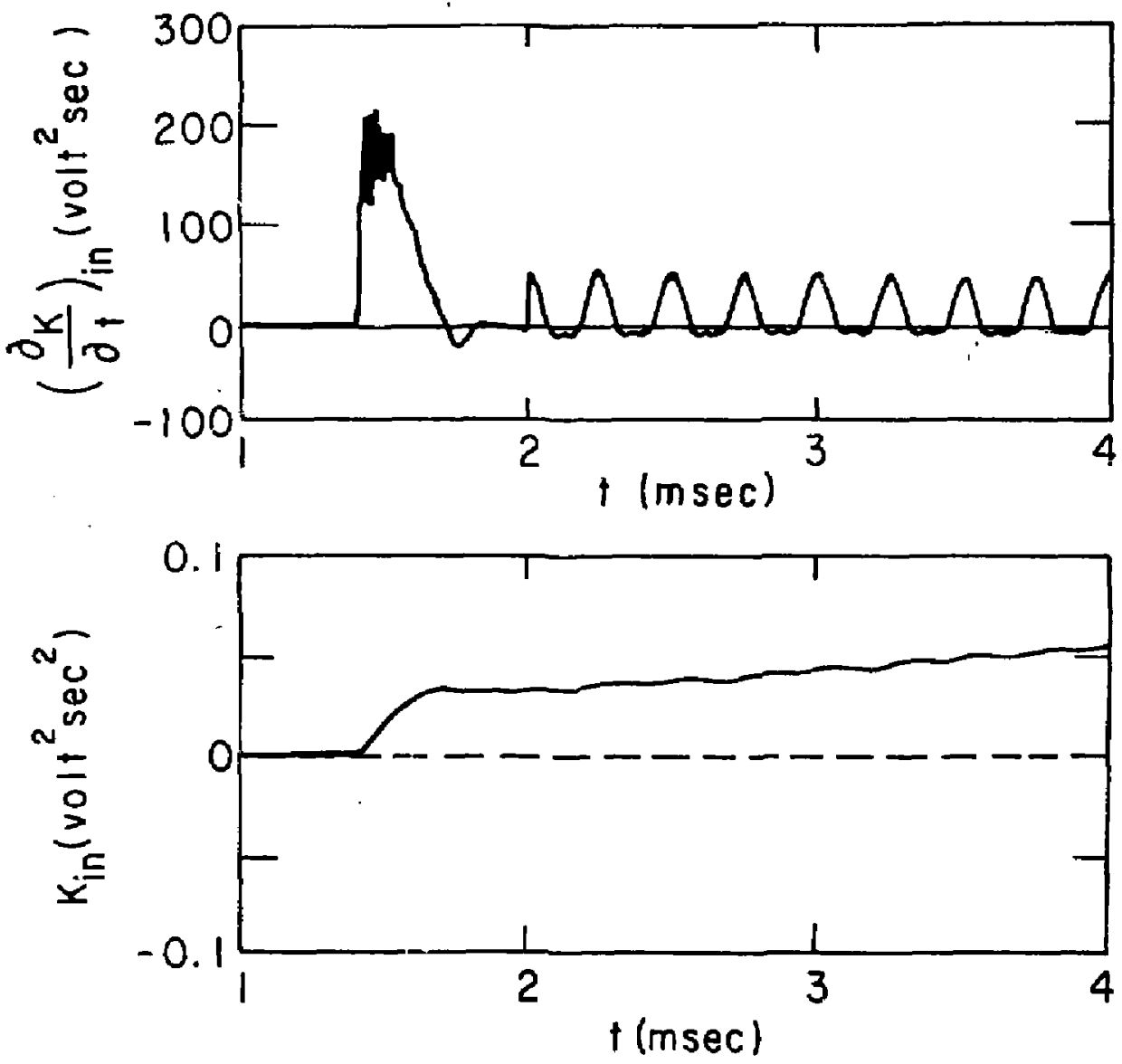

Fig. $3 b$ 
Plosme Ras Lob, Austro Nat'll Univ, Australla

Dr. Frank J. Pooloni, Unir of wollongong, AUSTRALIA

Prot. I.R. Jones, FIinders Un IV., AustRaLIA

Prot. M.H. Erennan, UnIv Sydnoy, NUSTRALIA

Prot. F. Cad. Inst Theo Phys, AUSTEIA

Frof. Frank Verheest, Inst theoretisehe, BELGILM

Dr. D. Palumbo, Dg XII Fusion Prog, BELGILA

Ecole Royale Mllitalre, Lab de Phys Plasmas, BeLGiLM

Dr. P.H. Sakanoka, UnIv Estodual, BRAzIL

Or. C.R. James, UnIv of Alberta, CANADA

Prof. J. Tolchmenti, Univ of Mentrae I, CAMDA

Dr. H.M. Skarsgard, Unlv of Soskatcheran, CNMADA

Prot. S,R, Sreenivasan, Universlty of Calgary, CANDA

Prof. Tudor W. Johnston, INRS-Energle, CANDA

Dr. Honthos Barnard, Un iv Brttish Columbla, CANAOA

Dr. M.P. Bochynskl, MPB Tochnologies, Inc., CNWDA

Zhenger Ll, Sh' Inst Physilcs, CHIM

Library. Ts Ing Hus Unlvoisity, CHiks

Librerlen, Institute of Physles, CHINA

Inst Plasma Phys, Acodemi sinica, CHIMA

Dr. Peter Lukac, Komenskeho Unlv, CZECHOSLOVAKIA

The Librarlan, Culhem Luboratory. ENGLAND

Prof, Schetzman, Observatolre do N1Ga, FRAKCE

3. Radet, CEH-3P6, FRMNCE

AK Dupas LIbrary, AM Dupas Librery, FRANCE

Dr. Tom Huel, Acodemy BIbllpgraphic, HONG KOWG

Preprint Llbrory, Cant Res Inst Phys, HUHGARY

Dr. S.K. Tresan, Fanjab UnIvorsity, IFDIA

Dr, Indra, Mohan Lal Das, Banares Hind! UnIV, IMDIA

Dr. L,K. Charda, South Gujarat iniv, INDiA

Dr, R_k, Chhojlanl, Yor Ruch I Morg, INDIA

P. Kaw, Physical Research Lab, INDIA

Dr. Phillip Rosenau, Israel Inst Tech, ISRaEL

Prot. 5. Cuperman, Tel Aviv Un lvers Ity. ISPAEL

Prot. G. Rostagn 1, Univ DI Padova, ITALY

Ll prarlen, Int'l Ctr Theo Phys, ITALy

Miss Clalla de Palo, Assoc ElRATOM-CNEN, ITALY

gIDIfoteca, del GNR EURATOM, ITALY

Dr, H. Yamoto, Toshlbe Res \& Dev, JAPAN

Prof. H. Yoshlkowo, JAERI. Toks I Ras Est, JAPAN

Prot. T. Uchida, Universtty of Tokyo, JaPAN

Research Info Center, Nagore Unlversity, JAPAN

Prof. Kyojl NishIkawa, Univ of HIToshimb, JaPAN

Prof. SlgorJ MorI, JAERI, JAPAN

Llerory, Kyoto University, JAPAN

Prot. Ichliro Kowokami, Nihon Univ, JAPAN

Prot. Satoshi Itoh, Kyushu Universlty, JAPAN

Toch Info Division, Kores Atomic Energy, KOAEA

Dr. R. England, CIudod Universitarie, MEXICO

Bl bllotheek, Fork-1nst Voor Plosme, NETHERLANDS

Prof, B.5. Liter, Unlversity of WeIketo, NEW ZEALAND

Dr. Surest: C. Shome, Unly of Calebar, NIGERIA
Prof. J.A.C. Cobral, Inst Suporlor Toch, PORTucal Dr. Octevion Petrus, ALI CURA InI isersity, Rowaria Prof. M. h. Hall berg, UnIverslty of Matal, SO AFRICA Dr. Johen de Vitlliors, Atonle Energy Bd, SO AFRICA Fusion DIV. LIbrary, JEN, SPAIN

Prof. Hans withelmon, Chalmars Untv Tech, SwEDEN Dr. Lennart Stentlo, University of UMEA, SWEDEN Library, Royal Inst Toch, SWEDEN

Dr. ErIk T. Karison, Uppsala UnIversltet, SwEDEN

Centre on Recherchesen, Ecole Polytech Fod, SwITZERLAND

Dr. Wol. Walse, Not'I Bur Stand, USA

Dr. W.M. Strecey, Georg Inst Teen, ULA

OT. S,T. Wu, Unir Aleowe, tish

Prof. Morman L. Oleson, Univ S ftor 1de, USA

Dr. Banjumin Ma, lowa Stote UnIv, USA

Prot. Magne Kristlensen, Taxas Toen Univ, USA

Dr. Fleymond Asker, Auburn Univ, USA

Dr. Y.T. Tolok, Khorkor Phys Toch Ins, USSR

Dr. D.D. Ryutov, SIberlan ACad Sel, USSR

Or. G.A. EIIseer, Kurchbtor Institute, USSR

Or. V.A. Glukhlkh, Inst Electro-Physled, USSR

institute Gen. Physics, USSR

Prof, T.J. Boyd, Unir colloge N Woles, HaLeS

Dr. K, Schindler, Ruhr Univorsitat, W. Geamany

Huclear Res Estab, Jullch Lid, $H$. GEFanAY

LIbrerlan, Haxt lanck Institut, H. GEPMANY

Or. H.J. Kaoppler, Unlversity Stutgart, W. GeRManY

BIbliothak, Inst Plosmoforschung, W. GERANY 